\title{
DOCTRINA DE GALENO SOBRE LAS CAUSAS EN LOS PULSOS. V: LAS CAUSAS SECUNDARIAS NATURALES Y NO-NATURALES*
}

\author{
Luis Miguel Pino Campos \\ Universidad de La Laguna \\ lmpino@ull.edu.es
}

\section{RESUMEN}

El libro III del tratado de Galeno titulado Sobre las causas en los pulsos explica las llamadas causas secundarias de alteración en los pulsos, las cuales se clasifican en tres clases, de las que en este libro Galeno describirá dos: las llamadas causas naturales y las causas no naturales. PALABRAS ClaVE: Medicina, Galeno, Esfigmología, Causas secundarias de alteración en los pulsos.

GALEN'S DOCTRINE ABOUT THE CAUSES IN THE PULSES.

V: THE NATURAL SECUNDARY CAUSES AND THE NON NATURAL ONES

\section{ABSTRACT}

The book III of the Galen's treatise entitled About the Causes in the Pulses explains the so-called secundary causes of alteration in the pulses, which are classified into three classes but in this book Galen will describe only two: the so-labelled natural causes and the non natural ones. KEY WORDS: Medicine, Galen, Sphygmology, Secundary Causes of alteration in the pulses.

\section{INTRODUCCIÓN}

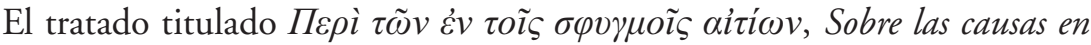
los pulsos, se divide en cuatro partes, a cada una de las cuales Galeno las denominó $\beta i \beta \lambda$ íov y las numeró con las letras del alfabeto $(\mathrm{A}, \mathrm{B}, \Gamma, \Delta)$. Del contenido de los dos primeros libros (A y B) nos hemos ocupado en estudios anteriores, en los que hemos comentado las causas sinécticas (o continentes), es decir, las causas primarias que pueden generar pulsos nuevos (causas primarias generadoras) o pueden alterar pulsos ya existentes (causas primarias alteradoras) ${ }^{1}$ :

- las causas generadoras, explicadas en el libro primero, afectan a la facultad elaboradora del pulso (entiéndase el corazón) y a los órganos que lo transmiten por todo el cuerpo (entiéndanse las arterias);

- las causas alteradoras del pulso son una o varias anomalías que se producen en el cuerpo y que afectan al corazón y a las arterias. En consecuencia, el pulso 
se altera de dos maneras posibles: las producidas por varias anomalías simultáneas, explicadas en los capítulos I-IV del libro segundo, y las producidas por una sola anomalía, explicadas en los capítulos V-XV del mismo libro. Estas anomalías que ocasionan la debilidad de la facultad o de los órganos son:

a) la acumulación de humores en las proximidades del corazón y de las arterias, la cual dificulta las actividades de éstos y, por tanto, no se pueden mover como sería necesario;

b) la obstrucción en los conductos sanguíneos, la cual impide el flujo normal de la sangre y entorpece su doble función: por un lado, transportar y distribuir el pneuma; por otro, mantener la temperatura corporal; y

c) la presión de órganos próximos al corazón o a las arterias, los cuales, al haberse inflamado por alguna anomalía, dificultan la actividad específica del corazón, de las arterias o de los dos al mismo tiempo.

En este nuevo estudio nos ocuparemos del libro III que explica las llamadas causas secundarias, clasificadas por el mismo Galeno en tres categorías: causas

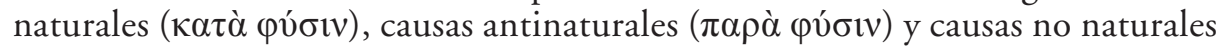
(oủ $\varphi v ́ \sigma \varepsilon 1)^{2}$.

\section{CAUSAS SECUNDARIAS DE ALTERACIÓN EN LOS PULSOS}

Tipos de causas secundarias. Las llamadas causas secundarias también alteran el pulso y son aquéllas que producen una segunda alteración en un pulso que ya antes había sido alterado por una causa primaria (generadora o alteradora) ${ }^{3}$. Las causas secundarias se clasifican en tres grupos: naturales, no-naturales y antinaturales (o preternaturales) $)^{4}$.

\section{CAUSAS NATURALES}

3.1. Hombres y mujeres tienen pulsos diferentes. Años antes de escribir el tratado Sobre las causas en los pulsos Galeno había escrito un pequeño resumen de su doctrina

\footnotetext{
* Este estudio forma parte del Proyecto de Investigación FFI2014-55220-R, 2015-2017, financiado por el Ministerio de Economía y Competitividad.

${ }^{1}$ Pino Campos (2015, 2016, 2017-18 y 2018).

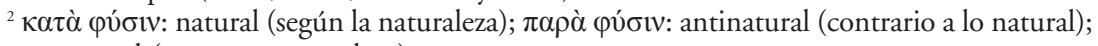

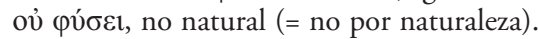

${ }^{3}$ Recuérdese que las causas primarias, llamadas también sinécticas, continentes o primeras, se subdividen en dos tipos: a) generadoras, las que generan pulsos nuevos porque la afección es de la facultad, entendida como el corazón, o de los órganos, entendidos como las arterias, y b) alteradoras, las que modifican el pulso por una causa ajena al corazón y a las arterias, cuales son las obstrucciones que impiden el flujo regular, las acumulaciones de humores y las presiones u opresiones de otros órganos que dificultan el movimiento arterial y cardíaco.

${ }^{4}$ Véase el capítulo primero del libro III.
} 


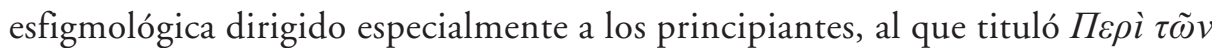

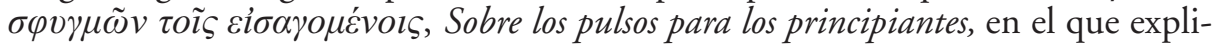
caba brevemente algunas causas de generación y de alteración de los pulsos, mencionaba otras causas sin definirlas y omitía otras más complejas, pues la finalidad de aquel libro era sólo que los principiantes practicaran la técnica de percibir los pulsos a través del tacto en las yemas de sus dedos gracias a aquellos iniciales conocimientos y prácticas que Galeno les transmitías.

Galeno recuerda que ya en aquel libro explicaba que el pulso de los varones era distinto del pulso de las mujeres: el del hombre era un pulso más lento, más grande, más vehemente y más raro que el de la mujer; en efecto, el de ésta era un pulso más rápido, más pequeño, más lánguido y más frecuente que el de aquél ${ }^{6}$.

En la definición de los pulsos Galeno suele utilizar cinco dimensiones habitualmente, pero no siempre las menciona todas, como ha sucedido en el caso anterior y hará a lo largo de este tratado, en el que habla del tamaño (pulso grande / pequeño, incluyendo las tres dimensiones espaciales) ${ }^{7}$, de la rapidez (pulso rápido / lento), de la vehemencia (pulso vehemente / lánguido) y de la frecuencia (pulso frecuente / raro). Pero hay otras dimensiones del pulso denominadas con sus respectivos términos, como son la dureza del golpe arterial contra el tacto (pulso duro / blando), el grosor o delgadez de la denominada túnica arterial (grueso / delgado), la tensión (pulso tenso / átono), etc. ${ }^{8}$

3.2. Los hombres «cálidos» y el pulso. Galeno habla después de los hombres que son cálidos por naturaleza, los cuales tienen los pulsos más grandes, más rápidos o veloces ${ }^{9}$ y mucho más frecuentes, pero, en cambio, no son mucho más vehementes. Conviene recordar que en todas las dimensiones en las que son medidos los pulsos se establecen tres medidas, de tal manera que si hablamos de "hombres cálidos"10,

${ }^{5}$ Véase nuestra traducción Sobre los pulsos para los principiantes (Madrid 2015).

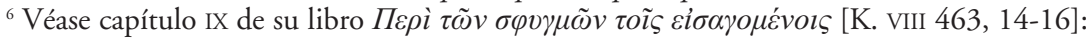

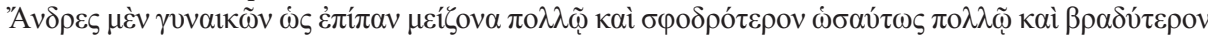

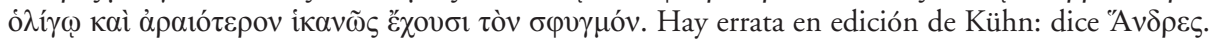

${ }^{7}$ Cuando Galeno habla de tamaño se refiere lógicamente a las dimensiones espaciales: longitud, anchura y altura (o profundidad, según se tome el pulso en la muñeca hacia arriba o hacia abajo, respectivamente); en cada dimensión Galeno distingue tres medidas: longitud (largo, mediano y corto), anchura (ancho, mediano y estrecho) y altura o profundidad (alto o profundo, mediano y bajo). Cuando en los pulsos se dan tres, o dos dimensiones al menos, con las medidas mayores (es decir: largo + ancho + alto, largo + alto, largo + ancho, o ancho + alto) se les denomina pulsos grandes, mientras que si ofrecen las medidas opuestas, se les denomina pulsos pequeños (corto + estrecho + bajo, corto + bajo, corto + estrecho, estrecho + bajo).

${ }^{8}$ Véase el capítulo segundo del libro III.

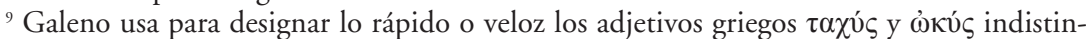
tamente.

${ }^{10}$ El término griego es $\theta \varepsilon \rho \mu o i ́$, y entendemos que se refiere a hombres cuya temperatura natural está habitualmente caliente, pero no hasta el punto de que pueda ser considerada febril. 
habríamos de entender que habrá hombres menos cálidos -con más humedad-, hombres más cálidos -con más sequedad- y hombres cálidos - equilibrados en humedad y sequedad- y -añade- podrían ser tal vez desequilibrados en cuanto a la temperatura.

Las medidas en estos pulsos deberían seguir siendo tres, si se habla del tamaño de los pulsos, es decir, grandes, medianos y pequeños; sin embargo, parece que Galeno incluye en este capítulo una subclasificación del tamaño, pues divide la medida "grande», que se opone a "pequeña» $\mathrm{y}$ «mediana», en otra escala de tres diferencias de lo grande: «pulsos grandes», «más grandes» $\mathrm{y}$ «mucho más grandes», sin que dé una explicación que justifique el cambio de criterio, es decir, admitir que sería posible, al menos en una de las tres dimensiones espaciales, subdividir el tamaño grande en tres tipos.

Hasta Galeno se habían explicado estos pulsos de una manera incompleta, según explica en este capítulo; añade, en consecuencia, que es necesario tener en cuenta, además, las crasis, es decir, los llamados temperamentos o constituciones corporales, que consisten en tener o no unas facultades más desarrolladas que otras. Así llama Galeno «hombres cálidos» a los que de cuatro facultades tienen una que destaca por encima de las otras tres. Y serán más cálidos los que tengan sus pulsos en la máxima dimensión de las siguientes magnitudes: más grandes, más veloces y más frecuentes. Faltaría en este caso hablar de la dimensión de la vehemencia / languidez, sobre la cual sólo afirma en sentido negativo que no pueden ser «mucho más vehementes». La razón parece estar en el hecho de que para hablar de la vehemencia del pulso es necesario tener en cuenta el concepto de ritmo del pulso, otra dimensión o diferencia del pulso, pulso rítmico o arrítmico, sin medida intermedia, de la que no ha hablado aún en este tratado, sino que sólo lo alude en este capítulo para desarrollarlo en otro momento ${ }^{11}$.

3.3. La delgadez y el pulso. Galeno dedica el siguiente capítulo ${ }^{12}$ a quienes tienen una constitución corporal delgada, en concreto, Galeno los denomina "los más delgados", en los cuales el pulso suele ser "más grande", "mucho más raro" y un "poco más vehemente". Si bien es frecuente leer las medidas -imprecisas- de Galeno distribuidas en tres niveles progresivos como, por ejemplo, "grande", "más grande" y "muy (o mucho más) grande", sorprende al lector que introduzca en ocasiones algunas variantes, como la que leemos en la dimensión de la vehemencia: se puede entender "vehemente", "más vehemente" y "mucho más vehemente"; en cambio, en este capítulo parece introducir una medida nueva cuando dice que los delgados pueden tener un pulso "poco más vehemente", lo cual nos obliga a preguntarnos si el mismo Galeno llegaba a distinguir, dentro de las siempre imprecisas medidas del pulso denominadas

\footnotetext{
${ }^{11}$ Véase capítulo tercero.

${ }^{12}$ Capítulo cuarto del libro III.
} 
"vehementes", una diferencia más junto a las ya citadas "vehemente", "más vehemente" y "mucho más vehemente", a la cual denominaría "poco más vehemente". Y si las diferenciaba, ¿cómo lo lograba?

Junto a la dificultad de interpretación de esta diferencia en la vehemencia del pulso, encontramos la aplicación lógica de Galeno a partir de unos datos que hemos de presumir como ciertos. Explica Galeno, en primer lugar, que si una persona es delgada, o bien, ha adelgazado, la arteria se podrá mover en la dilatación y en la contracción con más facilidad al disponer a su alrededor de más espacio y soportar un peso (presión) menor, porque los cuerpos o partes corporales, antes gruesos, que rodeaban la arteria son ahora más ligeros al haber adelgazado, y ello hace posible, en consecuencia, que los pulsos se dilaten y se contraigan en un tamaño adecuado al tener menos obstáculos en sus movimientos de dilatación y de contracción. En esta circunstancia es habitual que la función pulsística (distribución del pneuma y mantenimiento del calor natural) aumente el tamaño de los pulsos (con la consiguiente dilatación mayor de la arteria) y ello hará que los pulsos se hagan también más raros y mucho más raros (es decir, menos frecuentes y mucho menos frecuentes) en la misma medida que se hagan también más grandes o mucho más grandes.

Por su parte, la vehemencia aumentará en la misma medida en la que se dilate la arteria y ésta sea capaz de unirse (tocar o alcanzar) a los cuerpos más delgados con los que estaba en contacto. Esta circunstancia parece que añade tensión al pulso, pero, en realidad, lo que sucede es que este tipo de pulsos muestra más tensión de la que realmente tiene por haberse producido previamente un adelgazamiento. En estas personas delgadas no destaca la dimensión de rapidez y lentitud, como tampoco destaca en las personas más gruesas, siempre que la facultad sea vigorosa y la función esté bien.

3.4. Los pulsos según la edad. En el capítulo quinto recoge Galeno las diferencias de los pulsos según la edad, por tanto, es una causa natural, dentro de las llamadas causas secundarias que alteran los pulsos. Galeno opone las características de los pulsos de un recién nacido o de un niño pequeño a las de un anciano, de manera que los niños pequeños tienen los pulsos "muy frecuentes", "muy rápidos", "más vehementes" y "más grandes", mientras que los ancianos los tienen "muy raros", "muy lentos", "más lánguidos" y "más pequeños". En las edades intermedias entre niños $\mathrm{y}$ ancianos se dan los pulsos medianos entre los extremos indicados ${ }^{13}$.

A la hora de tomar el pulso sucede que la mayoría de los médicos no percibe la sístole, mientras que una minoría sí llega a percibirla después de un largo entrenamiento. Esta dificultad en percibir la sístole es la que lleva a Galeno a recomendar a los principiantes practicar la toma del pulso con el fin de percibir bien la diástole

${ }^{13}$ Esta es la síntesis de lo que encabeza el comienzo del capítulo quinto y coincide con lo que se dijo en el libro Los pulsos para principiantes. 
y la pausa que sigue hasta la siguiente diástole, a sabiendas de que esta percepción es sólo parcial, porque sólo percibe dos tiempos (diástole y pausa) de los cuatro de que consta un latido (diástole, pausa postdiastólica, sístole y pausa postsistólica), pero el mismo Galeno había comprobado que la mayoría de los médicos no tenían la sensibilidad suficiente en el tacto como para percibir esos cuatro tiempos. Según se perciban los cuatro tiempos del latido o sólo dos, se podrá determinar otra dimensión del pulso, el ritmo pulsístico. Sólo cuando un médico alcance el nivel de percepción de las dos pausas esfígmicas (postdiastólica y postsistólica), estará en condiciones de establecer el ritmo del pulso que cada paciente tiene ${ }^{14}$.

Galeno explica también los detalles de varias afecciones y su reflejo en el pulso. Es el caso, por ejemplo, de un niño (no de un recién nacido) que tiene fiebre (temperatura alta) y necesita algo que lo refrigere, lo habitual es que la refrigeración llegue por medio de pulsos grandes; si también consume muchos humores -los cuales sirven para el alimento y el crecimiento-, requerirán abundancia de sustancias y producirán muchos residuos fuliginosos; el consumo de humores y la eliminación de los residuos se facilitarán gracias a que las sístoles de los niños son muy grandes y el consumo de pneuma psíquico (anímico) aumenta para que los órganos puedan funcionar correctamente. Por otro lado, los movimientos de dilatación y de contracción son prácticamente iguales, dado que la arteria necesita recibir tantas sustancias como las que debe expulsar.

Comparados los pulsos de los niños con los de los ancianos, en los niños (etapa diferente de los recién nacidos) sus pulsos son medianos en rapidez y en tamaño tanto en la diástole como en la sístole, porque ya han dejado de tener los primeros pulsos de recién nacidos, los cuales eran muy rápidos y muy grandes. En cambio, el hecho de que los ancianos necesiten menos cantidad para alimentarse y refrigerarse, hace que la sístole sea en éstos más lenta que la diástole y como no necesitan nutrirse en tanta cantidad como cuando eran más jóvenes porque no consumen ya tanto ni van a crecer más, su necesidad de eliminar residuos es también menor. En los ancianos, por tanto, la dilatación es menor, pues sólo necesitan que el calor natural se ventile y que haya suficiente pneuma psíquico que los mantenga. Si nos fijamos en la rareza ${ }^{15}$ del pulso de los ancianos, observaremos que es mucho mayor que

${ }^{14}$ Recuérdese que en cada latido hay dos pausas: la postdiastólica (más fácil de percibir al comenzar la pausa inmediatamente después de finalizar la dilatación arterial) y la postsistólica, que se inicia tras la sístole o contracción arterial, más difícil de percibir. En cuanto al ritmo, anunciará al final de este capítulo que lo explicará cuando comente los pronósticos de los pulsos, es decir, en el tratado Sobre el pronóstico a partir de los pulsos.

${ }^{15}$ En el ámbito esfigmológico la "rareza" del pulso o el pulso raro alude, para los que sólo perciben la diástole, a un tipo de pulso que viene dado por la duración que hay desde el final de una diástole hasta el comienzo de la diástole siguiente; cuando ese tiempo dura más de lo normal se denomina "pulso raro", mientras que si ese tiempo dura menos, se denomina pulso "frecuente". En cambio, los que tienen una sensibilidad mayor en el tacto y pueden distinguir los cuatro tiempos del pulso (diástole, pausa postdiastólica, sístole y pausa postsistólica) miden sólo la pausa postdiastólica, porque es este descanso tras el movimiento diastólico el que refleja mejor el estado del pulso. Así pues, pulso raro es el que tiene una pausa larga; pulso frecuente es el que tiene una pausa corta. 
el cambio que experimenta hacia la lentitud, y ello coincide con el hecho de que la pausa es mucho más larga y que el movimiento es continuo, porque la función pulsística no se completa enteramente, aunque aumente su tamaño.

Galeno alude a la tensión del pulso, pero no se detiene en explicarla en este capítulo. En cambio, sí recuerda que la función de cada movimiento pulsístico es máxima en los recién nacidos, mientras que es mínima en los ancianos. A ello añade que la sístole es un movimiento de contracción que va disminuyendo con el paso de los años, y más aún en los ancianos. Finaliza el capítulo recordando que el pulso de los adultos es más vehemente y más lánguido que el de los ancianos, porque la facultad en los adultos es muy vigorosa, mientras que en los ancianos es muy débil, de tal manera que según sea el vigor o la debilidad de la facultad así se diferenciarán en vehemencia y languidez.

3.5. El pulso y las estaciones anuales. El capítulo sexto del libro tercero está dedicado a las alteraciones de los pulsos producidas según las estaciones del año (segunda causa natural), que son similares a las alteraciones que se producen durante el día (tercera causa natural). Sostiene Galeno la idea de que según la etapa de cada una de las estaciones anuales así serán los pulsos dominantes; su exposición respondería al siguiente esquema:

\begin{tabular}{|c|c|c|c|}
\hline & $\begin{array}{l}\text { INICIO DE LA } \\
\text { ESTACIÓN ANUAL }\end{array}$ & $\begin{array}{l}\text { CENTRO DE LA } \\
\text { ESTACIÓN ANUAL }\end{array}$ & $\begin{array}{l}\text { FINAL DE LA } \\
\text { ESTACIÓN ANUAL }\end{array}$ \\
\hline PRIMAVERA & $\begin{array}{l}\text { Similar al final del otoño: } \\
\text { pulsos pequeños, lángui- } \\
\text { dos, lentos y raros. }\end{array}$ & $\begin{array}{l}\text { Como en las horas centrales } \\
\text { del día: pulsos muy grandes } \\
\text { y muy vehementes. }\end{array}$ & $\begin{array}{l}\text { Similar al inicio del otoño: } \\
\text { pulsos grandes, vehementes, } \\
\text { rápidos y frecuentes. }\end{array}$ \\
\hline VERANO & $\begin{array}{l}\text { Similar al final del verano: } \\
\text { pulsos pequeños, lángui- } \\
\text { dos, rápidos y frecuentes; }\end{array}$ & $\begin{array}{l}\text { Es unas veces similar al } \\
\text { invierno central, otras veces } \\
\text { es opuesto, esto es: pulsos } \\
\text { grandes y vehementes, rápi- } \\
\text { dos y frecuentes. }\end{array}$ & $\begin{array}{l}\text { Similar al inicio del verano: } \\
\text { pulsos pequeños, lánguidos, } \\
\text { rápidos y frecuentes; }\end{array}$ \\
\hline OTOÑO & $\begin{array}{l}\text { Similar al final de la prima- } \\
\text { vera: pulsos grandes, vehe- } \\
\text { mentes, rápidos y frecuen- } \\
\text { tes; }\end{array}$ & $\begin{array}{l}\text { Pulsos moderados en rapidez } \\
\text { y moderados en frecuencia; }\end{array}$ & $\begin{array}{l}\text { Similar al inicio de la prima- } \\
\text { vera: pulsos pequeños, lángui- } \\
\text { dos, lentos y raros; }\end{array}$ \\
\hline INVIERNO & $\begin{array}{l}\text { Pulsos pequeños, lángui- } \\
\text { dos, lentos y raros; }\end{array}$ & $\begin{array}{l}\text { Pulsos pequeños, vehemen- } \\
\text { tes, lentos y raros. }\end{array}$ & $\begin{array}{l}\text { Pulsos menos grandes, menos } \\
\text { vehementes, más rápidos y } \\
\text { más frecuentes; }\end{array}$ \\
\hline
\end{tabular}

Es cierto que Galeno plantea unas alteraciones del pulso según las estaciones del año y distingue en ellas épocas iniciales, centrales y finales como si se tratara de una ecuación matemática, si bien reconoce que su descripción responde a una consideración general y no individual para cada paciente. Es consciente de que ha generalizado las consecuencias para el pulso cuando admite que los cambios estacionales no siempre producen las mismas características que en años anteriores.

Tras esta descripción de los efectos en el pulso de la causa natural de las estaciones anuales, pasa a describir los efectos que cada estación anual produce en los tres apartados que constituyen el pulso: el corazón (o facultad), las arterias (u órganos) 
y la función que estos dos órganos (corazón y arterias) realizan en el cuerpo. Por ejemplo, Galeno señala que en la época central de la primavera el aire que nos envuelve es muy saludable, por lo que también los cuerpos están sanos generalmente; ello significa que esos cuerpos saludables son muy vigorosos por su facultades, muy poderosos por sus temperaturas y muy moderados por los órganos, de tal manera que no se empapan por exceso de humedad ni se arrugan por exceso de sequedad, como tampoco se hielan ni congelan por el frío, ni se debilitan ni abandonan por exceso de calor. Recuerda que escribió un tratado titulado Sobre el diagnóstico de los pulsos para que los médicos conocieran los cambios de los pulsos según las edades, las estaciones anuales, las regiones y otras circunstancias semejantes.

3.6. El pulso y las regiones terrestres. En el breve capítulo séptimo Galeno establece una equivalencia general de las alteraciones de los pulsos según las regiones terrestres tal y como ha explicado anteriormente al hablar de los pulsos según las estaciones anuales, de tal manera que los pulsos en las regiones terrestres frías serán como los pulsos propios de la estación invernal, entendida como de la época central del invierno; los pulsos de las personas que vivan en zonas templadas, serán como los pulsos característicos de la época central de la primavera y de manera análoga en las restantes regiones.

Del mismo modo aplica análogamente la distribución general de los pulsos según las situaciones del aire que nos envuelve: los aires cálidos producirán los pulsos como en las estaciones anuales cálidas (es decir, como en el verano), los aires fríos producirán los pulsos como en las estaciones anuales frías (es decir, como en el invierno) y los aires de temperatura mediana producirán los pulsos como en las estaciones anuales medianas, refiriéndose éstas a la primavera.

3.7. El pulso de las embarazadas y del embrión. Otro breve capítulo, el octavo, está dedicado a la circunstancia del embarazo, en la cual-afirma Galeno- los pulsos se alteran al hacerse más grandes, más frecuentes y más rápidos. Es evidente que en esta circunstancia, al mismo tiempo que aumenta la frecuencia y rapidez del pulso, aumenta también la respiración, porque consume más cantidad de pneuma (pulsación) y de aire (respiración), pues lo necesita no sólo para ella sino también para el feto. En cambio, el pulso no se hace más vehemente ni más lánguido, ni tampoco más duro ni más blando, sino que se mantiene en una medida mediana en estas dos magnitudes. Concluye afirmando que lo relacionado con el estado de una embarazada no altera lo que es propio de la facultad (corazón) ni de los órganos (arterias).

3.8. El pulso y el sueño tras las comidas. En el siguiente capítulo, noveno, Galeno habla de otra causa natural de alteración del pulso: se trata del sueño. Explica que al comienzo de los sueños, los pulsos son más pequeños, más lánguidos, más lentos y más raros; conforme pasa el tiempo de sueño y, en especial, si es después de una comida, los pulsos se hacen aún más lentos y más raros todavía. En la parte final del sueño los pulsos se hacen más grandes y más vehementes, pero de nuevo vuelven a la pequeñez y languidez, conservando la lentitud y rareza. 
Reconoce Galeno que la facultad del cuerpo de hacer la digestión se elabora mejor si su acción se produce durante el sueño. La digestión, cuando se duerme, es al principio más débil y pesada, después, elaborada una parte de esa digestión, se robustece y entra en calor; esto ocurre tanto en los que ingieren alimentos calientes como fríos: el movimiento digestivo hace que, pasado un tiempo, el cuerpo entre en calor. Hipócrates ya lo explicaba cuando admitía que la elaboración del alimento durante la digestión se hace tanto despierto como dormido.

Galeno pasa a explicar el proceso de alteración de los pulsos durante la digestión: cuando la facultad está pesada y, aún peor, en el comienzo de los sueños, los pulsos son más pequeños y más lánguidos (Erasístrato afirma que ello se debe a la pausa de los movimientos voluntarios), pero cuando la facultad se ha fortalecido, los pulsos se hacen más grandes y más vehementes, porque el calor aumenta mientras se realiza la digestión y elabora los humores, de acuerdo con las opiniones de Hipócrates y de otros médicos y filósofos, para quienes el calor interior que se produce en la digestión interviene claramente en los sueños. Ese calor interior aumenta al máximo cuando ya ha elaborado por completo los humores, lo cual no significa que los pulsos se hagan lentos y raros.

Para Galeno el proceso digestivo y su influencia en los pulsos se debe al siguiente proceso: si el calor externo disminuye en los que duermen, domina en ellos el calor interior, que altera el pulso haciendo las sístoles más largas y las diástoles más lentas. Sucede, en cambio, que cuando el médico que toma el pulso no percibe la sístole sino sólo la diástole, interpreta que el pulso es lento, porque la diástole es lenta, pero la sístole (que no percibe) le parece rápida: esta diferencia entre quienes perciben sólo la diástole y quienes perciben los cuatro tiempos del pulso (diástole, pausa postdiastólica, sístole y pausa postsistólica) lleva a los primeros a confundir el tamaño largo de la sístole (que para ellos comprende: pausa postdiastólica, sístole y pausa postsistólica) con la lentitud de la diástole. Y aclara Galeno: ambos movimientos de diástole y de sístole son lentos. Cuando el médico puede distinguir con su tacto la diástole, la sístole y las dos pausas, comprueba que los dos movimientos, diástole y sístole, son lentos, pero el tiempo de la diástole es corto, mientras que el de la sístole es largo, tiempo de la sístole más largo al que se añaden los tiempos de las dos pausas en aquellos que sólo perciben la diástole.

Este pulso de los dormidos se caracteriza por el hecho de que su contracción (sístole) es grande, mientras que la dilatación es menor (pulso pequeño). En resumen, el pulso de los dormidos es más pequeño y más lánguido que el de los despiertos, para luego hacerse grandes y vehementes; es lento en las diástoles y rápido en las sístoles, siendo más perceptible la vehemencia en las sístoles, porque la arteria agrega hollín. Una vez que la digestión ha terminado y si el hombre siguiera durmiendo, el sueño puede ser desmedido, pero los pulsos serán más pequeños, lentos, lánguidos (o débiles) y raros. Afirmará Galeno que cuando el pulso avanza en pequeñez, languidez, lentitud y rareza está cerca de la muerte. Elogia a Hipócrates y a Herófilo por sus aciertos, mientras critica por sus errores a Arquígenes y a Apolonides.

3.9. El pulso en los sueños nocturnos. Galeno dedica el siguiente capítulo, décimo, a los efectos que el sueño produce en el pulso. Afirma que en un estado 
de salud normal pasar de estar despierto a estar dormido se produce en poco tiempo, es decir, es un cambio de estado (despierto a dormido) más rápido que el pasar de dormido a despierto. Cuando una circunstancia inhabitual, como pueden ser sueños perturbadores (pesadillas), ruidos inhabituales o movimientos bruscos de un cuerpo dormido, alteran el sueño de forma rápida y repentina. El que se despierta de forma repentina, tiende a expulsar fuera el calor natural, lo cual perjudica el estado de su cuerpo. Resulta que este calor natural produce el sueño realmente porque ese calor natural se convierte en alimento (reparador) de cierta fatiga o sequedad, o bien, porque no puede expulsar fuera del cuerpo un exceso de humedad que ha acumulado; mientras que en el primer caso el sueño repara la fatiga y sequedad, en el segundo se produce un daño grave al no poder expulsar el exceso de humedad, lo que implica en este segundo caso que la salud del cuerpo empeora y puede producir efectos similares al coma y al letargo. Tanto los sueños como las vigilias necesitan humedad y sequedad en las adecuadas cantidades; para que haya una secreción de los residuos es necesario también que se produzcan movimientos vehementes y fuertes para que esa humedad sea agitada y retirada de tal manera que queden libres los poros y favorezcan la respiración y transpiración. En el momento de despertar de los sueños los pulsos son grandes, vehementes y rápidos, con un poco de vibración por la violencia de los movimientos iniciales, pero al poco tiempo vuelven a la simetría natural.

3.10. El pulso según delgadez o gordura o según crasis cálidas o frías. En los capítulos siguientes (XI-XII) dedica una breve referencia a los pulsos propios de aquellos hábitos adquiridos, como puede ser el pulso delgado, propio del que está delgado y el pulso grueso, del que está grueso; o según las constituciones corporales (o crasis) que compara con los pulsos propios de las estaciones anuales: las crasis cálidas elaboran los pulsos como son en las estaciones anuales cálidas, y las frías, como en las frías; las húmedas y secas, como en las estaciones anuales húmedas y secas respectivamente, a lo que añade que la dureza es propia de las crasis y estaciones anuales secas, mientras que la blandura acompaña a las húmedas.

\section{LAS CAUSAS NO NATURALES}

4.1. El pulso en los ejercicios físicos. Cambia Galeno en el capítulo XIII a las llamadas "causas no naturales", ov̉ el ejercicio físico (gimnasia, deportes, equitación, etc., o esfuerzos desmesurados y agotadores). Por un lado, cuando los ejercicios son moderados los pulsos son vehementes, grandes, rápidos y frecuentes, pero si el ejercicio fuera superior a lo que la facultad puede hacer en condiciones normales, los pulsos se vuelven lánguidos, pequeños, pero rápidos y frecuentes en cantidades desmedidas, hasta el punto de que el deportista se agota y no puede moverse. Y si continuara en su ejercicio podría llegar a tener por ello los pulsos lánguidos, pequeños, lentos y raros hasta que se agotara la facultad, necesitaría pausas intermedias, en las que el cuerpo se enfriaría. Explica Galeno que en los ejercicios la facultad utiliza toda la tensión, lo que hace los pulsos vehementes, aumenta la función (las arterias distribuyen más pneuma y calor natural) y los pulsos 
se vuelven grandes y rápidos, y también frecuentes porque tienen que consumir más pneuma y calor natural. Cuando la facultad de los que hacen ejercicios está cansada, tiene los pulsos pequeños y lánguidos, porque está debilitada, muy frecuentes por el agotamiento de la función, y lentos.

\begin{tabular}{c|c|c|c|c|c}
\hline Ejercicios & \multicolumn{5}{|c}{ Facultad elabora los pulsos con tensión } \\
\hline Moderados & Vehementes & Grandes & Rápidos & Frecuentes & $\begin{array}{c}\text { Aumenta la función: } \\
\text { las arterias distribuyen } \\
\text { más pneuma y más calor } \\
\text { natural }\end{array}$ \\
\hline $\begin{array}{c}\text { Esforzados } \\
\text { con cansancio }\end{array}$ & Lánguidos & Pequeños & Muy rápidos & Muy frecuentes & Facultad cansada \\
\hline Agotadores & Lánguidos & Pequeños & Lentos & Raros & $\begin{array}{c}\text { Facultad agotada; necesita } \\
\text { pausas para recuperarse y } \\
\text { el cuerpo se enfría. }\end{array}$ \\
\hline $\begin{array}{c}\text { Facultad debili- } \\
\text { tada y agotada }\end{array}$ & Lánguidos & Pequeños & Lentos & Muy frecuentes & $\begin{array}{c}\text { Función agotada en distri- } \\
\text { bución de pneuma y de } \\
\text { calor natural }\end{array}$ \\
\hline
\end{tabular}

4.2. El pulso y los baños calientes. En el capítulo décimo cuarto explica Galeno que la segunda causa no-natural de alteración de los pulsos es la de los baños que puede tomar una persona en unas circunstancias inadecuadas. Ante todo Galeno explica que los baños son de una utilidad completa para el cuerpo, pero que han de tomarse cuando el cuerpo reúna unas condiciones determinadas y el agua también las reúna. Por ejemplo, no son convenientes los baños cuando se está cansado, acalorado, enfriado o reseco, ni cuando se está ansioso o se nota que el cuerpo está en un estado anómalo o necesitado de una evacuación. Es preferible en estas circunstancias esperar un tiempo a que el cuerpo recupere su normalidad, es decir, que esté descansado, haya recuperado su temperatura normal (ni acalorada ni enfriada), haya adquirido la humedad conveniente y haya evacuado si hubiese necesidad. En estas circunstancias Galeno afirma que los baños calientes moderados, tomados a temperatura templada y durante un tiempo no excesivo, benefician a los pulsos porque la facultad es la debida y la función aumenta en la cantidad adecuada.

En cambio, los baños excesivos alteran los pulsos, porque la facultad tiene que elaborarlos con más frecuencia y con la misma rapidez que antes, porque, de lo contrario, podría causar un fallecimiento. De darse esas condiciones malignas por los baños excesivos o desmedidos, aparecerían los pulsos formicantes.

Cuando el cuerpo ya no apetece tomar baños ni desmedidos ni normales, indica que ese cuerpo se ha enfriado completamente y que la facultad se ha disuelto, de manera que los pulsos cambian al tipo propio de una facultad debilitada y de una función disuelta, es decir, la facultad (corazón) no puede mantener la acción del movimiento pulsístico ni las arterias pueden distribuir el pneuma ni el calor natural, porque el cuerpo ya no lo produce en la cantidad necesaria ni con la rapidez exigida.

Así pues, estas dos causas no naturales (ejercicios físicos y baños templados), producen alteraciones de los pulsos cuando el cuerpo realiza ejercicios de forma exagerada o toma baños de agua templada de forma desmedida. 
4.3. El pulso y los baños fríos. En el capítulo décimo quinto explica Galeno que también los baños fríos pueden causar alteraciones de los pulsos, porque el agua fría enseguida enfría el cuerpo, y en este caso el cuerpo se puede fortalecer o debilitar. Si el cuerpo enfriado no recupera el calor, se producirá en él un entumecimiento, que elabora los pulsos de manera análoga, es decir: los baños fríos hacen los pulsos pequeños, más lánguidos, lentos y raros; tras este enfriamiento, el cuerpo puede reaccionar debilitándose más hasta el entumecimiento total, o bien, se fortalecerá, haciendo los pulsos vehementes, grandes, moderados en rapidez y frecuencia. En estos baños fríos el calor es mayor en el movimiento externo (diástole) que en el interno (sístole).

\begin{tabular}{c|l|l|c|c}
\hline $\begin{array}{c}\text { Baños fríos } \\
\text { con debilitamiento }\end{array}$ & Más lánguidos & Pequeños & Lentos & Raros \\
\hline $\begin{array}{c}\text { Baños fríos } \\
\text { con fortalecimiento }\end{array}$ & Vehementes & Grandes & $\begin{array}{c}\text { Moderados } \\
\text { en rapidez }\end{array}$ & $\begin{array}{c}\text { Moderados } \\
\text { en frecuencia }\end{array}$ \\
\hline
\end{tabular}

4.4. El pulso y las comidas excesivas. En el capítulo décimo sexto recuerda Galeno que en el libro de los pulsos para los principiantes escribió algo en relación con los efectos dañinos que pueden producir las comidas abundantes, esto es, que la facultad (corazón) se vuelve pesada y los pulsos se hacen anómalos y desordenados. De estos pulsos había hablado Erasístrato en su libro Acerca del arte médica, sobre cuyo contenido Galeno manifestaba su discrepancia. Recuerda también la opinión de Arquígenes, quien afirmaba que las comidas abundantes oprimían la facultad (corazón) y convertían los pulsos, por un lado, en más lánguidos y más pequeños, por otro lado, en mucho más rápidos y frecuentes, opinión de Arquígenes que vuelve a recordar al final del capítulo por su inexactitud.

Galeno, sin ánimo de polemizar dirá, corrigiendo a Arquígenes, que tal vez el de Apamea quiso decir, a pesar de que se equivocaba, que esos pulsos eran anómalos y que su anomalía consistía en ser muchos más los pulsos rápidos que los pulsos lentos, o que los pulsos frecuentes eran muchos más que los raros. Pero en uno y otro caso lo dicho por Arquígenes era erróneo.

Galeno entiende, por su parte, que cuando se ha comido mucho, efectivamente la facultad se siente presionada por la abundancia y, en consecuencia, elabora pulsos anómalos y desordenados. A consecuencia de la anomalía, aparecen unos daños en la facultad (corazón), de tal manera que si se produjeran muchos pulsos grandes y vehementes y entre ellos se encontraran unos pocos pulsos pequeños y lánguidos, significaría que el daño de la facultad sería pequeño. Si, al contrario, los pulsos grandes y vehementes fueran pocos y fueran muchos los pulsos pequeños y lánguidos, el daño en la facultad sería muy grande. Por otro lado, si los pulsos fueran continuadamente pequeños y lánguidos, la facultad se disolvería completamente.

Mientras las facultades sean fuertes por sí mismas, aunque estén presionadas y oprimidas por algo, los pulsos vehementes y lánguidos se mezclan totalmente, sin que importe el hecho de que la facultad esté dañada. Y recuerda que los daños más leves de la facultad elaboran los pulsos más rápidos que frecuentes, mientras que los daños más grabes los elaboran más frecuentes que rápidos. 


\begin{tabular}{|c|c|c|c|c|}
\hline Facultad & Pulso & Tamaño y vehemencia & Rapidez y frecuencia \\
\hline $\begin{array}{c}\text { Facultad } \\
\text { presionada }\end{array}$ & $\begin{array}{c}\text { Facultad } \\
\text { poco dañada }\end{array}$ & $\begin{array}{c}\text { Pulsos } \\
\text { anómalos }\end{array}$ & $\begin{array}{c}\text { Muchos pulsos vehementes y } \\
\text { grandes mezclados con pocos } \\
\text { pulsos lánguidos } \\
\text { y pequeños }\end{array}$ & \\
\hline $\begin{array}{c}\text { Facultad } \\
\text { presionada }\end{array}$ & $\begin{array}{c}\text { Facultad } \\
\text { muy dañada }\end{array}$ & $\begin{array}{c}\text { Pulsos } \\
\text { anómalos }\end{array}$ & $\begin{array}{c}\text { Pocos pulsos vehementes } \\
\text { y grandes mezclados } \\
\text { con muchos pulsos lánguidos } \\
\text { y pequeños }\end{array}$ & \\
\hline $\begin{array}{c}\text { Facultad } \\
\text { debilitada }\end{array}$ & $\begin{array}{c}\text { Facultad } \\
\text { con daños } \\
\text { graves }\end{array}$ & $\begin{array}{c}\text { Pulsos } \\
\text { desordenados }\end{array}$ & $\begin{array}{c}\text { Pulsos pequeños y lánguidos } \\
\text { continuamente }\end{array}$ & $\begin{array}{c}\text { Pulsos más frecuentes } \\
\text { que rápidos }\end{array}$ \\
\hline $\begin{array}{c}\text { Facultad } \\
\text { vigorosa, } \\
\text { presionada } \\
\text { u oprimida }\end{array}$ & $\begin{array}{c}\text { Facultad } \\
\text { con daños } \\
\text { leves }\end{array}$ & $\begin{array}{c}\text { Pulsos } \\
\text { anómalos }\end{array}$ & $\begin{array}{c}\text { Pulsos vehementes y lángui- } \\
\text { dos mezclados }\end{array}$ & $\begin{array}{c}\text { Pulsos más rápidos } \\
\text { que frecuentes }\end{array}$ \\
\hline $\begin{array}{c}\text { Facultad } \\
\text { oprimida }\end{array}$ & \multicolumn{3}{|c|}{$\begin{array}{c}\text { Pulsos anómalos } \\
\text { y desordenados }\end{array}$} & \\
\hline
\end{tabular}

4.5. El pulso y la bebida de vino. Finaliza el libro tercero con el capítulo décimo séptimo, en el que habla sobre todo de la alteración del pulso que produce el vino; esta alteración del pulso es más breve que la alteración producida por la comida, debido a que el vino aumenta mucho más la rapidez y el tamaño del pulso que la vehemencia y la frecuencia. Galeno establece una correspondencia entre la comida y el vino moderado, de forma tal que en la medida en la que el alimento moderado ofrece un vigor [a la facultad] más vehemente y más constante, en la misma medida el vino eleva también el tamaño del pulso. Ello es debido a que lo que añade el vino es rápido al ser húmedo y cálido: cuando el cuerpo requiere aumentar la cantidad [en la nutrición], lo más rápido es un remedio húmedo y si éste es conducido por el calor, se requiere más cantidad. También es rápida la evacuación de la comida. La bebida del vino es también de digestión rápida y de corta duración al ser una bebida muy evaporable. El hecho de que el vino sea considerado una parte de la alimentación es causa de alteración del pulso, y dado que el vino calienta más que los alimentos sólidos, añadirá también más tamaño y rapidez al pulso.

4.6. Pasa a explicar brevemente las causas más difíciles de entender en la alteración de algunos pulsos. Se refiere a los pulsos vermiculante y formicante. El pulso vermiculante se da en los procesos de cóleras, en los fuertes flujos de vientre, en los flujos femeninos y en las disoluciones de la facultad por evacuación del cuerpo, mientras que el pulso formicante se da en las disoluciones de la facultad (corazón) por fiebre maligna. En estos casos es necesario que el pulso sea completamente lento y raro, aunque en las fiebres agudas esto no es posible, de hecho son siempre malignas, porque la abundancia de temperatura (fiebre) no puede producir un pulso lento ni raro.

Finaliza este tercer libro con el anuncio de que en el cuarto hablará de las

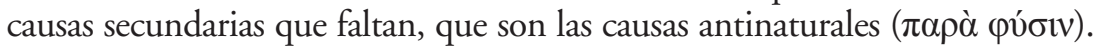




\section{CONCLUSIÓN}

Hasta aquí el contenido del libro tercero del tratado que Galeno dedicó a explicar dos tipos de causas secundarias que alteraban los pulsos: las causas secundarias naturales y las causas secundarias no naturales. Hemos comentado estos dos tipos de causas, naturales y no naturales, ambas tipificadas de una manera muy lógica, en cuanto que su clasificación responde a si son así por naturaleza o lo son por hábitos adquiridos: entre las primeras ha aludido a los pulsos alterados por causas secundarias naturales, como son las que conciernen al sexo de machos y de hembras, la temperatura, el estado normal de delgadez, la edad, las estaciones anuales, las regiones terrestres, las mujeres embarazadas y el pulso de su embrión, el sueño tras las comidas, los sueños nocturnos, el cambio que significa estar delgado o grueso por naturaleza y los pulsos que producen las crasis o constituciones corporales cálidas o frías; entre las segundas, las no naturales, ha aludido a los ejercicios físicos, baños calientes, baños fríos, comidas excesivas, bebidas moderadas de vino, y de algunas enfermedades singulares que producen los pulsos vermiculantes y los formicantes.

Llama la atención el complejo panorama esfigmológico que se presenta ante el médico que se especializa en diagnosticar las afecciones del cuerpo a través del pulso, porque este ejercicio debía de exigirle disponer no sólo de una aguda sensibilidad táctil y de un amplio conocimiento de las afecciones internas por medio de otros síntomas, sino también saber recetar los remedios apropiados que hicieran retornar los pulsos a sus estados habituales, cuando ello fuera posible.

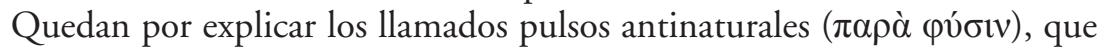
serán explicados en el cuarto y último libro de este tratado y de cuyo comentario nos ocuparemos en un próximo estudio.

RECIBIDO: enero 2018; ACEPTADO: enero 2018.

\section{BIBLIOGRAFÍA (SELECCIÓN)}

BRAIN, P. (1986): Galen on bloodletting. A study of the origins, development and validity of his opinions, with a translation of the three works, Cambridge University Press, Cambridge.

DAREMBerG, Charles (1879 - 1963): "Recherches sur la sphygmologie antique", en Ch. DAREMberG y Ch. E. Ruelle, Oeuvres de Rufus d'Ephèse, París, 1879, Amsterdam, 1963', pp. 219-232.

DeICHGrÄBER, Karl (1956 - 1984): “Galen als Erforscher des menschlichen Pulses. Ein Beitrag zur Selbstdarstellung des Wissenschaftlers (De dignotione pulsuum, I.1)”, SB d. Deutschen Akademie d. Wiss. Kl.f. Sprachen, Lit. u. Kunst 3: 1-41 [Berlín 1957] [= H. GÄrTnER, E. HeITSCH, U. SCHINDEL (1984): Ausgewählte Kleine Schriften, Hildesheim, Munich, Zurich, pp. 288-326].

FLEMING, D. (1955): "Galen on the motions of the blood in the heart and lungs", Isis 46: 14-21.

FURLEY, David J. - WILKIE, J. S. (eds.) (1984): Galen: On respiration and the arteries. An edition with English translation and commentary of De usu respirationis; An in arteriis natura sanguis contineatur; De usu pulsuum, and De causis respirationis, Princeton U.P. [pp 194-227] [Edición bilingüe greco-inglesa]. 
GAROFALO, Ivan (1998): "Le commentaire ravennate au De pulsibus ad tirones de Galien: le commentaire et ses sources”, en C. DEROUX (ed.): Maladie et maladies dans les textes latins antiques et médiévaux, Bruxelles (Collection Latomus, vol. 242), pp. 382-392.

Garofalo, I., - Vegetti, M. (1978): Opere scelte di Galeno, Turín.

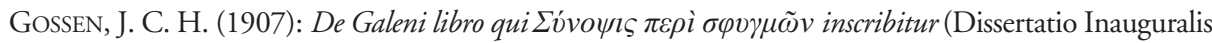
Philologica), Berlín.

Gotfredsen, E. (1942): “Oldtidens Laere om Hjerte, Kar og Puls”, Acta Hist. Scient. Nat. Med. 1, Copenhague, pp. 317-42.

HARRIS, C. R. S. (1973): The heart and vascular system in ancient Greek Medicine from Alcmeon to Galen, Oxford [267-431; 440-455].

Horine, E. F. (1941): “An Epitome of Ancient Pulse Lore”, Bulletin of the History of Medicine X.1: 209-249.

López Férez, Juan Antonio (1991): Galeno: obra, pensamiento e influencia, UNED, Madrid.

MaY, Margaret Tallmadge (1968): Galen. On the Usefulness of the Parts of the Body, Cornel University Press, Ithaca, Nueva York, dos vols.

Mitaritonna, O. (1968): "Il pensiero di Galeno sul movimento del cuore", Collana di Pagine di Storia della Medicina, Miscell. 19: 133-143.

NiebYL, P. H. (1971): “The non-naturals causes”. Bull. Hist. Med. 45: 486-492.

Palmieri, Nicoletta (1999): Agnellus de Ravenne, Commentaire sur le De pulsibus ad tirones de Galien. Intr. texte latin. (Adiuuante I. GAROFALO), traduction, commentaire par... Thèse d'habilitation, Grenoble.

Pino Campos, Luis Miguel (2004): "Léxico esfígmico antiguo y su pervivencia en nuestros días", en J. A. LÓPEZ FÉrez (ed.), La lengua científica griega: orígenes, desarrollo e influencias en las lenguas modernas europeas. III, Ediciones Clásicas, Madrid, pp. 209-238.

Pino Campos, Luis Miguel (2005a): Galeno: Sinopsis de Galeno de su propia obra sobre pulsos, Ediciones Clásicas, Colección Obras de Galeno: Gal. 5, Madrid.

PINO CAMPOS, Luis Miguel (2005b): "La doctrina galénica del pulso: síntesis del libro Sobre la utilidad de los pulsos”, Actas del XI Congreso Español de Estudios Clásicos, Madrid, v. II, pp. 477-486.

Pino Campos, Luis Miguel (2006): "Observaciones al tratado de Galeno Acerca de la diferencia de los pulsos”, Fortunatae 17: 99-115.

Pino Campos, Luis Miguel (2010): Galeno. Sobre la diferencia de los pulsos, Ediciones Clásicas, Colección Obras de Galeno: Gal. 7, Madrid.

Pino CAmpos, Luis Miguel (2015a): "Consideraciones en torno al tratado galénico De causis pulsuum", en Actas del XIV CEEC [Barcelona, 6-10 de julio de 2015], SEEC, vol. 1, pp. 621-629.

Pino Campos, Luis Miguel (2015b): Galeno. Los pulsos para principiantes. La utilidad de los pulsos, Ediciones Clásicas, Colección Obras de Galeno: Gal. 10, Madrid.

Pino Campos, Luis Miguel (2016): "Doctrina de Galeno sobre las causas de los pulsos. II: Introducción, casuística y comentarios", Fortunatae 27: 119-144.

Pino CAmpos, Luis Miguel (2017-18): "Doctrina de Galeno sobre las causas de los pulsos. IV: casos y comentarios", Fortunatae 28: 287-298.

PINO CAMPOS, Luis Miguel (2018): "Doctrina de Galeno sobre las causas de los pulsos. III: casos y comentarios”, en L. Conti, E. Crespo, M.E. Rodríguez Blanco, E. Torrego, J. DE la Villa 
(coords.), Philos hetaîros. Homenaje al profesor Luis M. Macía, Servicio de Publicaciones de la Universidad Autónoma de Madrid, Madrid, pp. 87-96.

Ruiz Moreno, Aníbal y Tovar, Antonio (1948): Obras de Galeno, Publicaciones del Instituto de Historia de la Medicina (Facultad de Ciencias Médicas), vol. XII, t. I, Buenos Aires [Contiene los textos titulados Compendio del pulso para los estudiantes y De las diferencias de pulsos].

SÁnCheZ Granjel, Luis (1961): "La circulación de la sangre según Galeno”, Boletín de la Sociedad Española de Historia de la Medicina 1.2: 4 ss.

SCHADEWALDT, Otto (1866): Sphygmologiae historia inde ab antiquissimis temporibus usque ad aetatem Paracelsi, Tesis, Berlín. 